\title{
Size effects of graphene nanoplatelets on the properties of high-density polyethylene nanocomposites: morphological, thermal, electrical, and mechanical characterization
}

\author{
Tuba Evgin ${ }^{*} 1,2$, Alpaslan Turgut ${ }^{2}$, Georges Hamaoui ${ }^{3}$, Zdenko Spitalsky ${ }^{4}$, Nicolas Horny ${ }^{3}$, \\ Matej Micusik ${ }^{4}$, Mihai Chirtoc ${ }^{3}$, Mehmet Sarikanat ${ }^{5}$ and Maria Omastova ${ }^{4}$
}

\section{Full Research Paper}

\section{Address:}

1Dokuz Eylul University, The Graduate School of Natural and Applied Sciences, Mechanical Engineering Department, Tinaztepe Campus, 35397, Buca, Izmir, Turkey, ²Dokuz Eylul University, Engineering Faculty, Mechanical Engineering Department, Tinaztepe Campus, 35397, Buca, Izmir, Turkey, ${ }^{3}$ GRESPI, Multiscale Thermophysics Lab, Université de Reims Champagne-Ardenne URCA, Reims, France, ${ }^{4}$ Polymer Institute, SAS, Dúbravská cesta 9, 84541 Bratislava, Slovak Republic and ${ }^{5}$ Department of Mechanical Engineering, Ege University, 35100, Bornova, Izmir, Turkey

Email:

Tuba Evgin* - tuba.evgin@deu.edu.tr

* Corresponding author

Keywords:

electrical properties; graphene nanoplatelets; mechanical properties; polymer matrix composites (PMCs); thermal properties
Beilstein J. Nanotechnol. 2020, 11, 167-179.

doi:10.3762/bjnano.11.14

Received: 28 June 2019

Accepted: 10 December 2019

Published: 14 January 2020

This paper is dedicated to the memory of our colleague, Prof. Ismail Tavman, who recently passed away.

Associate Editor: S. Giordani

(C) 2020 Evgin et al.; licensee Beilstein-Institut. License and terms: see end of document.

\begin{abstract}
High-density polyethylene (HDPE)-based nanocomposites incorporating three different types of graphene nanoplatelets (GnPs) were fabricated to investigate the size effects of GnPs in terms of both lateral size and thickness on the morphological, thermal, electrical, and mechanical properties. The results show that the inclusion of GnPs enhance the thermal, electrical, and mechanical properties of HDPE-based nanocomposites regardless of GnP size. Nevertheless, the most significant enhancement of the thermal and electrical conductivities and the lowest electrical percolation threshold were achieved with GnPs of a larger lateral size. This could have been attributed to the fact that the GnPs of larger lateral size exhibited a better dispersion in HDPE and formed conductive pathways easily observable in scanning electron microscope (SEM) images. Our results show that the lateral size of GnPs was a more regulating factor for the above-mentioned nanocomposite properties compared to their thickness. For a given lateral size, thinner GnPs showed significantly higher electrical conductivity and a lower percolation threshold than thicker ones. On the other hand, in terms of thermal conductivity, a remarkable amount of enhancement was observed only above a certain filler concentration. The results demonstrate that GnPs with smaller lateral size and larger thickness lead to lower enhancement of the samples' mechanical properties due to poorer dispersion compared to the others. In addition, the size of the GnPs had no considerable effect on the melting and crystallization properties of the HDPE/GnP nanocomposites.
\end{abstract}




\section{Introduction}

In recent years, electrically and thermally conductive polymer nanocomposites have attracted considerable attention because of their potential use in many industrial applications, such as aerospace, electronics, packaging, automotives, sensors, batteries, anti-statics, light-emitting devices, and corrosionresistant coatings $[1,2]$. The addition of a conductive filler to the polymeric matrix is one of the easiest methods to produce these nanocomposites. Among conductive filler materials, carbon-based materials are attractive since they show significant enhancement of the properties of the nanocomposites at relatively low filler concentration compared to others [1,3,4]. Using graphene, a single-atom-thick structure of $\mathrm{sp}^{2}$ hybridized carbon atoms in a hexagonal arrangement, is of great interest due to its large specific surface area, 2D structure, and superior inherent properties, such as its thermal (1000-5000 W/mK [5]) and electrical conductivity (6000 S/cm [6]), and mechanical properties (a Young's modulus of $1 \mathrm{TPa}$ and a tensile strength of $130 \mathrm{GPa}$ [7]). However, the mass production of graphene with high quality at a low cost is still challenging using available production technologies [8]. GnPs, formed by several graphene layers bonded together by van der Waals forces, are a potential alternative to graphene since they exhibit interesting properties and their fabrication cost is lower $[8,9]$.

Numerous studies performed on nanocomposites with graphene or its derivatives have shown that the properties of nanocomposites depend on several factors, such as the polymer type, morphology, intrinsic properties, size and defect level of the filler material, production method, interface between filler and polymer, and others [10-12]. Although the size of GnPs is one of the most important factors, only few studies have investigated the size effect of GnPs on the properties of nanocomposites with various matrices, such as HDPE [13-15], polypropylene (PP) $[8,9,16,17]$, epoxy [18-20], and polycarbonate (PC) [21] in the range of about $0.1-50 \mathrm{wt} \%(0.05-25 \mathrm{vol} \%)$. To the best of our knowledge, there has been no study on how the morphological, thermal, electrical, and mechanical properties of HDPEbased nanocomposites correlate with the size of GnPs in terms of thickness and lateral size. The objective of this study was to investigate the size effect of GnPs on the above-mentioned properties of HDPE-based nanocomposites. Considering the concentration of HDPE-based nanocomposites with GnP inclusions studied in the literature, the maximum concentration was up to $15 \mathrm{vol} \%$. This study was carried out within the range of 0.92-13.92 vol \% (2.05-26.81 wt \%) of GnP concentration.

\section{Results and Discussion Characterization}

The SEM micrographs of each type of GnP and nanocomposites with $5.52 \mathrm{vol} \% \mathrm{GnPs}$ are presented in Figure 1. The aggre- gated forms of the GnPs were observed due to their high surface energy. Figure 1 indicated that the particles of GnP types G1, G2, and G3 included many sharp edges and were irregularly shaped. As shown in Figure 1, it could be observed that the average lateral sizes of G1 and G2 were generally higher than those of G3, while G3 showed the lowest thickness. Furthermore, SEM images of the cryofractured surfaces of the HDPE/ GnP nanocomposites with 5.52 vol \% GnPs are shown in Figure 1d, Figure 1e, and Figure 1f to compare their structures. All types of GnPs were randomly and homogeneously distributed throughout the HDPE matrix where these layers separated the GnP nanoflakes. Two different dispersions of GnPs in HDPE were observed: separately dispersed and aggregated. The observed aggregates of GnPs, especially G3, may have been attributed to the large aspect ratio and high surface energy of the GnPs. In particullar, G1 nanoflakes were more isolated from each other, while G2 nanoflakes were found to be in more contact with each other. It is obvious from Figure 1 that G2 could form filler networks more easily than G1 and G3. From this study, it can be proposed that HDPE-based nanocomposites with G2 may show a greater number of GnP pathways and consequently higher electrical and thermal conductivity values. Additionally, G3 was seen to have better dispersion when compared to G1 containing the HDPE nanocomposites.

XPS sample analysis gave more information on the GnPs' chemical composition. The XPS results of GnPs are shown in Figure 2 and Table 1 . The GnPs generally showed a strong signal for carbon $(\mathrm{C} 1 \mathrm{~s}$ at $\approx 284.6 \mathrm{eV}$ ) and contained a small amount of oxygen (O $1 \mathrm{~s}$ at $\approx 531-534 \mathrm{eV}$ ). The $\mathrm{C} 1$ s peak centered at $\approx 284.6 \mathrm{eV}$, with an asymmetry towards higher binding energies, which is characteristic for an $\mathrm{sp}^{2}$ carbon atom. The broad peak observed at ca. $291 \mathrm{eV}$ (labeled 'Pi-Pi*' in Figure $2 b$ ) occurred due to the existence of delocalized $\pi$ electrons (conduction electrons) available for shake-up events following core electron photoemission (Thermo Fisher Scientific Avantage Data System 5.9904; Thermo Fisher XPS: Knowledge Base). In Table 1, the deconvolution fit for the $\mathrm{C} 1 \mathrm{~s}$ and $\mathrm{O} 1 \mathrm{~s}$ signals is also shown. Besides graphitic carbon signals $\left(\mathrm{sp}^{2}\right.$, centered at ca. $284.6 \mathrm{eV}$ ), signals for $\mathrm{C}-\mathrm{O}$ (ca. $286.4 \mathrm{eV}$ ), $\mathrm{C}=\mathrm{O}(287.4 \mathrm{eV})$, and $\mathrm{OC}=\mathrm{O}(289.2 \mathrm{eV})$ groups were detected. These signals correspond to the $\mathrm{O} 1 \mathrm{~s}$ signals of $\mathrm{C}=\mathrm{O}$ aromatic $\left(\mathrm{C}=\mathrm{O}_{\mathrm{ar}}\right.$, centered at ca. $\left.531.2 \mathrm{eV}\right), \mathrm{C}=\mathrm{O}$ aliphatic $\left(\mathrm{C}=\mathrm{O}_{\mathrm{al}}\right.$, centered at ca. $532.2 \mathrm{eV}$ ), $\mathrm{C}-\mathrm{O}$ (ca. $533.5 \mathrm{eV}$ ), and $\mathrm{O}_{2} \mathrm{C}=\mathrm{O}$ (ca. $535.8 \mathrm{eV}$ ) groups. The $\mathrm{C} 1 \mathrm{~s}$ signals of $\mathrm{GnPs}$ were approximately the same (Table 1 and Figure 2b). It was clear that G2 showed the highest atomic content of C 1s (98.4\%), and the surface of G2 was the least oxidized one. This reduced degree of oxidization of G2 was easily indicated by the low amount of carbonyl $\left(\mathrm{C}=\mathrm{O}_{\mathrm{ar}}\right)$ in the case of the $\mathrm{O} 1 \mathrm{~s}$ signal. There was also 


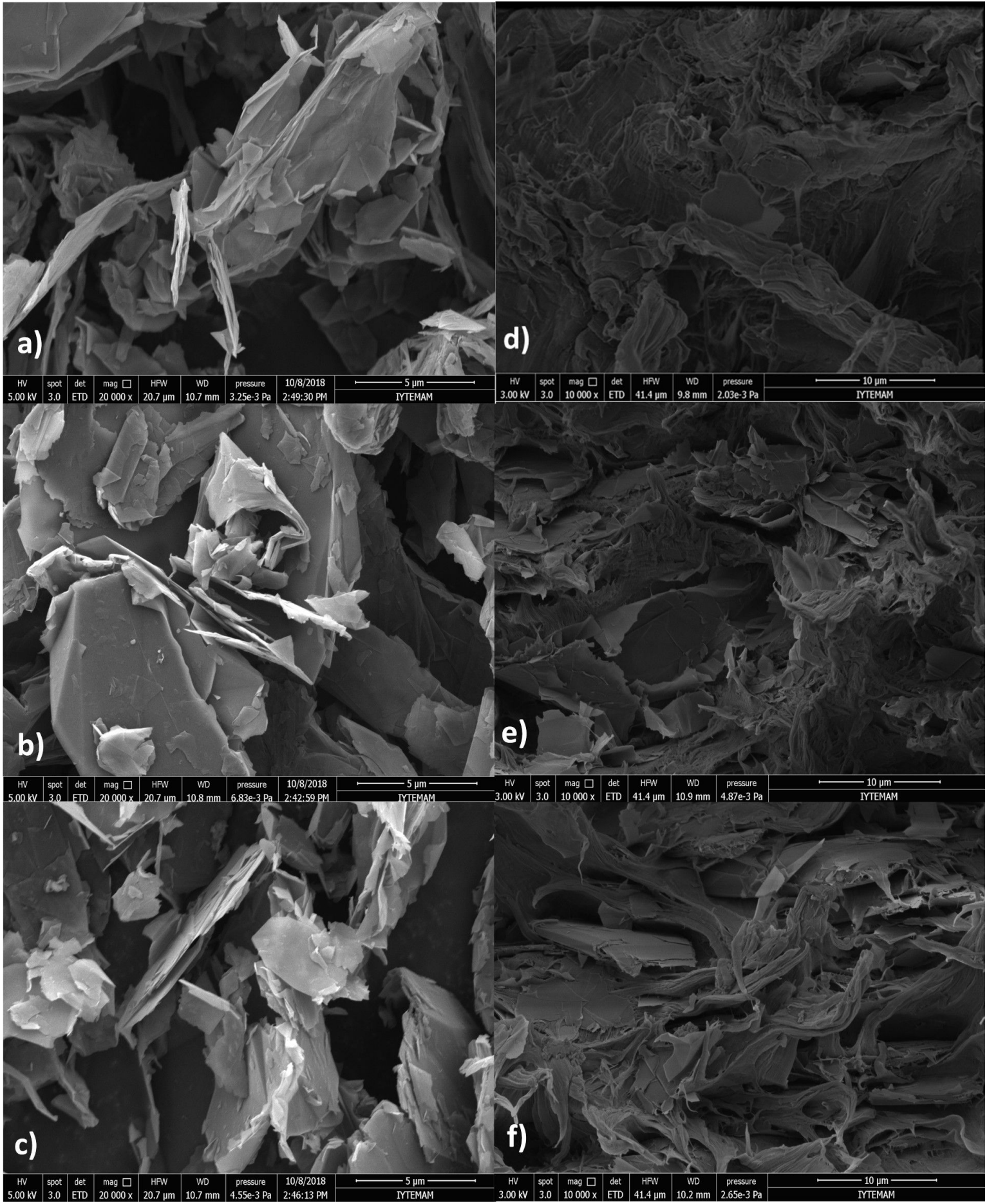

Figure 1: SEM images of a) G1, b) G2, c) G3, d) HDPE/G1 nanocomposite with 5.52 vol \%, e) HDPE/G2 nanocomposite with 5.52 vol \%, and f) HDPE/G3 nanocomposite with 5.52 vol \%.

a small amount of surface contamination present in the case of G1, with 0.1 atom $\%$ of Si $2 \mathrm{p}$ at ca. 103.6, corresponding to siloxanes, and 0.1 atom \% sodium ( $\mathrm{Na} 1 \mathrm{~s}$ at ca. $1072.1 \mathrm{eV}$ ). For $\mathrm{G} 3$, some contamination with sulfur was observed $(0.3$ atom $\%$, $\mathrm{S} 2 \mathrm{p}$ at $\approx 164-169 \mathrm{eV})$. However, the small differences in the
GnPs' surfaces' chemical composition did not affect the properties of the HDPE-based nanocomposites.

The results of FTIR analysis are shown in Figure 3a (further details can be found in Figures S1-S7, Supporting Information 

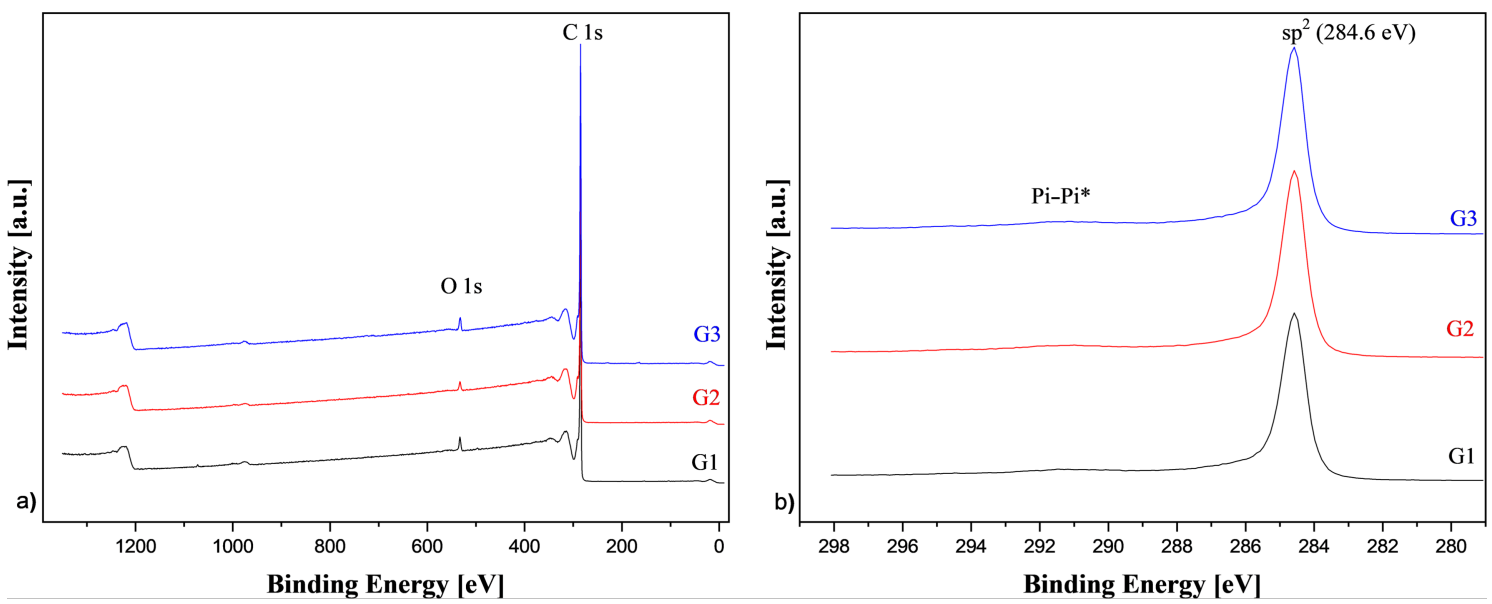

Figure 2: XPS: a) survey and b) C 1s high-resolution spectra for G1, G2, and G3.

Table 1: Apparent surface chemical composition of GnPs, as determined by XPS.

\begin{tabular}{|c|c|c|c|}
\hline \multirow[t]{2}{*}{ sample } & \multicolumn{3}{|c|}{ surface chemical composition (atom \%) } \\
\hline & $\begin{array}{l}\text { C } 1 \mathrm{~s} \\
\mathrm{sp}^{2} / \mathrm{sp}^{3} / \mathrm{C}-\mathrm{O} / \mathrm{C}=\mathrm{O} / \mathrm{OC}=\mathrm{O} / \Pi-\Pi^{*}\end{array}$ & $\begin{array}{l}\mathrm{O} 1 \mathrm{~s} \\
\mathrm{C}=\mathrm{O}_{\mathrm{ar}} / \mathrm{C}=\mathrm{O}_{\mathrm{a}} \mathrm{l} / \mathrm{C}-\mathrm{O} / \mathrm{O}_{2} \mathrm{C}=\mathrm{O}\end{array}$ & $\mathrm{S} 2 \mathrm{p} / \mathrm{Na} 1 \mathrm{~s} / \mathrm{Si} 2 \mathrm{p}$ \\
\hline G1 & $\begin{array}{l}97.2 \\
66.5 / 21.0 / 2.2 / 1.1 / 0.4 / 5.9\end{array}$ & $\begin{array}{l}2.6 \\
0.7 / 1.0 / 0.7 / 0.2\end{array}$ & $-/ 0.1 / 0.1$ \\
\hline G2 & $\begin{array}{l}98.4 \\
67.3 / 21.6 / 1.9 / 1.0 / 0.4 / 6.2\end{array}$ & $\begin{array}{l}1.6 \\
0.3 / 0.8 / 0.4 / 0.1\end{array}$ & $-/-/-$ \\
\hline G3 & $\begin{array}{l}97.3 \\
65.1 / 21.8 / 2.1 / 1.4 / 0.6 / 6.3\end{array}$ & $\begin{array}{l}2.4 \\
0.8 / 0.8 / 0.7 / 0.1\end{array}$ & $0.3 /-1-$ \\
\hline
\end{tabular}
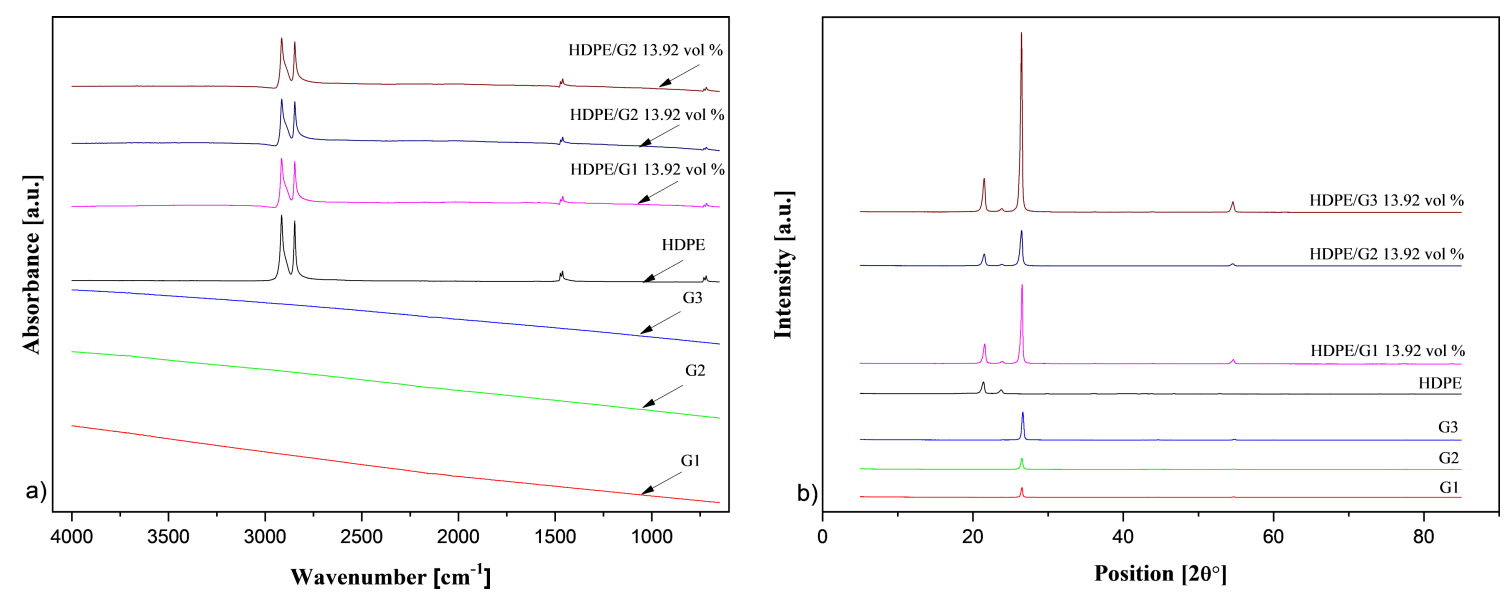

Figure 3: a) FTIR spectrum and b) XRD pattern of the GnPs, pure HDPE, and HDPE/13.94 vol \% GnP nanocomposites.

File 1). The spectrum of HDPE showed two strong peaks at $2914.86 \mathrm{~cm}^{-1}$ and $2847.37 \mathrm{~cm}^{-1}$, respectively, and four weak peaks at $1472.59 \mathrm{~cm}^{-1}, 1462.11 \mathrm{~cm}^{-1}, 730.28 \mathrm{~cm}^{-1}$, and $718.84 \mathrm{~cm}^{-1}$. The peaks at $\approx 2914 \mathrm{~cm}^{-1}$ and $\approx 2847 \mathrm{~cm}^{-1}$ were assigned to alkyl $(\mathrm{C}-\mathrm{H})$ stretch vibrations. The peaks at the wave numbers $\approx 1471 \mathrm{~cm}^{-1}$ and $\approx 1462 \mathrm{~cm}^{-1}$ were related to the $-\mathrm{CH}_{2}$ group's binding vibrations. The absorption peaks at $\approx 730 \mathrm{~cm}^{-1}$ and $\approx 718 \mathrm{~cm}^{-1}$ were attributed to aromatic $\mathrm{C}-\mathrm{H}$ bending. As seen in Figure 3a, all GnPs did not display any peak assigned to functional groups on their surface. The curves 
of HDPE and HDPE/GnP nanocomposites had almost the same absorption peaks. The size and content of the GnPs caused no change in the characteristic peaks of the HDPE matrix.

Additionally, the crystalline structures of GnPs, HDPE, and HDPE/GnP nanocomposites were studied, and their XRD patterns are shown in Figure $3 \mathrm{~b}$ (see also Figures S8-S10 in Supporting Information File 1). All types of GnPs showed a sharp peak at $2 \theta \approx 26.5^{\circ}$ and a weak peak at $2 \theta \approx 54.6^{\circ}$ corresponding to the (002) and (004) carbon reflections, respectively. The size of the GnPs did not cause a significant difference in the GnPs' crystalline structure. The sharp peak located at $2 \theta \approx 26.5^{\circ}$ was characteristic for hexagonal GnPs, with a $\mathrm{d}$-spacing of 0.336 . Two strong peaks centered at $2 \theta=21.38^{\circ}$ and $2 \theta=23.75^{\circ}$, corresponding to the (110) and (200) reflections of the HDPE orthorhombic phase, respectively, and two weak peaks centered at $2 \theta=29.93^{\circ}$ and $36.13^{\circ}$, corresponding to the (210) and (020) reflection planes, respectively, were clearly seen in the XRD pattern of pure HDPE. Similar HDPE peaks were observed by Sever and co-workers [22] and Wang and co-workers [23]. In the XRD patterns of the HDPE/GnP nanocomposites, the intensities of the peaks at $2 \theta \approx 21.4^{\circ}$ and $2 \theta \approx 23.8^{\circ}$ decreased with increasing $\mathrm{GnP}$ loading, while the intensities of the peaks at $2 \theta \approx 26.5^{\circ}$ and $2 \theta \approx 54.6^{\circ}$ increased. The XRD pattern of the HDPE-based nanocomposites exhibited a mix of the peaks appearing for HDPE and the GnPs. In the XRD patterns of the HDPE/GnP nanocomposites, the intensities of the peaks at $2 \theta \approx 21.4^{\circ}$ and $2 \theta \approx 23.8^{\circ}$ decreased with increasing $\mathrm{GnP}$ loading, while the intensities of the peaks at $2 \theta \approx 26.5^{\circ}$ and $2 \theta \approx 54.6^{\circ}$ increased. This was due to incorporation of GnP particles into the HDPE matrix. It was observed that all planes, which displayed considerable peak growth with the existence of GnPs, were in the general form of the $(00 \mathrm{x})$ type, being crystallographically in line with the $\mathrm{GnP}(002)$ plane. It has been indicated that GnPs may act as nucleation sites and that nucleation starts around the GnPs [8]. Figure $3 b$ shows that the size of the GnPs had only a slight effect on the reflection peaks of the HDPE/GnP nanocomposites, but the peak's intensity was influenced stronger.

\section{Electrical conductivity}

Figure $4 \mathrm{a}-\mathrm{c}$ demonstrate the AC conductivity $\left(\sigma^{\prime}{ }_{\mathrm{AC}}\right)$ of all $\mathrm{HDPE} / \mathrm{GnP}$ nanocomposites, measured at room temperature as a function of frequency. Pure HDPE is an insulating material that has a characteristic dielectric behavior corresponding to a linear increase in AC conductivity with increasing frequency [24]. The electrical conductivity of the nanocomposites increased with increasing amount of GnP. The reason for this increase may have been that a greater number of electrons was conducted through the HDPE/GnP interface because frequency facilitated the hopping of electrons [20]. For the HDPE/G1 nanocomposites, no significant enhancement of the electrical conductivity was observed. Figure 4a shows that the HDPE/G1 nanocomposites demonstrated the same linear behavior as pure HDPE for all GnP concentrations. A similar behavior was also exhibited by the HDPE/G2 and HDPE/G3 nanocomposites below a certain concentration, called the percolation threshold, which is defined as the minimum filler concentration where the insulating material is converted to a conductive or semiconductive material [25]. Above the percolation threshold, the dependence of the electrical conductivity on the frequency showed two different parts: i) the conductivity did not depend on the frequency up to a critical value, followed by ii) a regime in which the conductivity was dependent on the frequency. The first part was linked to the transfer of charge carriers by direct contacts between the GnP filler, while the second part reflected the conductivity due to hopping and tunneling of electrons between adjacent particles [26]. It was apparent that the critical frequency shifted towards higher frequencies, and the AC conductivity increases with increasing GnP loading.

Figure $4 \mathrm{~d}$ shows the variation in $\sigma^{\prime}{ }_{\mathrm{AC}}$ at $0.1 \mathrm{~Hz}$ for pure HDPE and the HDPE/GnP nanocomposites as a function of GnP content. Pure HDPE demonstrated a characteristic insulator behavior, with an electrical conductivity of $4.68 \times 10^{-17} \mathrm{~S} / \mathrm{cm}$, which was typical for polymers. For all GnP loadings, the HDPE/G1 nanocomposites were insulating, while it could clearly be seen that at GnP concentrations higher than 5.52 vol \% for G2 and 7.38 vol \% for G3, respectively, the HDPE-based nanocomposites became conductive. The nanocomposites showed a nonlinear increase in conductivity as a function of filler content. The HDPE/G2 and HDPE/G3 nanocomposites exhibited a characteristic S-shaped curve divided in three parts: insulating, transitioning, and conducting [27]. As seen in Figure 4d, the electrical conductivity of the nanocomposites was approximately the same up to the percolation threshold for each type of nanocomposite. As the GnP loading reached the percolation threshold, there was an abrupt increase in electrical conductivity because a conductive network was formed. The percolation threshold varied in terms of the size of GnPs, as mentioned by Bakir and co-workers [12]. The percolation thresholds of G2 and G3 were 5.52 vol \% and 7.38 vol \%, respectively. However, the percolation threshold was not observed for the HDPE/G1 nanocomposite, which should appear at higher concentrations. Nevertheless, with a filler concentration of $13.92 \mathrm{vol} \%$, the electrical conductivity of the HDPE/G2 nanocomposite was approximately one order of magnitude higher than that of the HDPE/G3 nanocomposite with the same filler content.

Furthermore, one of the most important parameters for the percolation threshold was the aspect ratio of the GnPs [28]. 

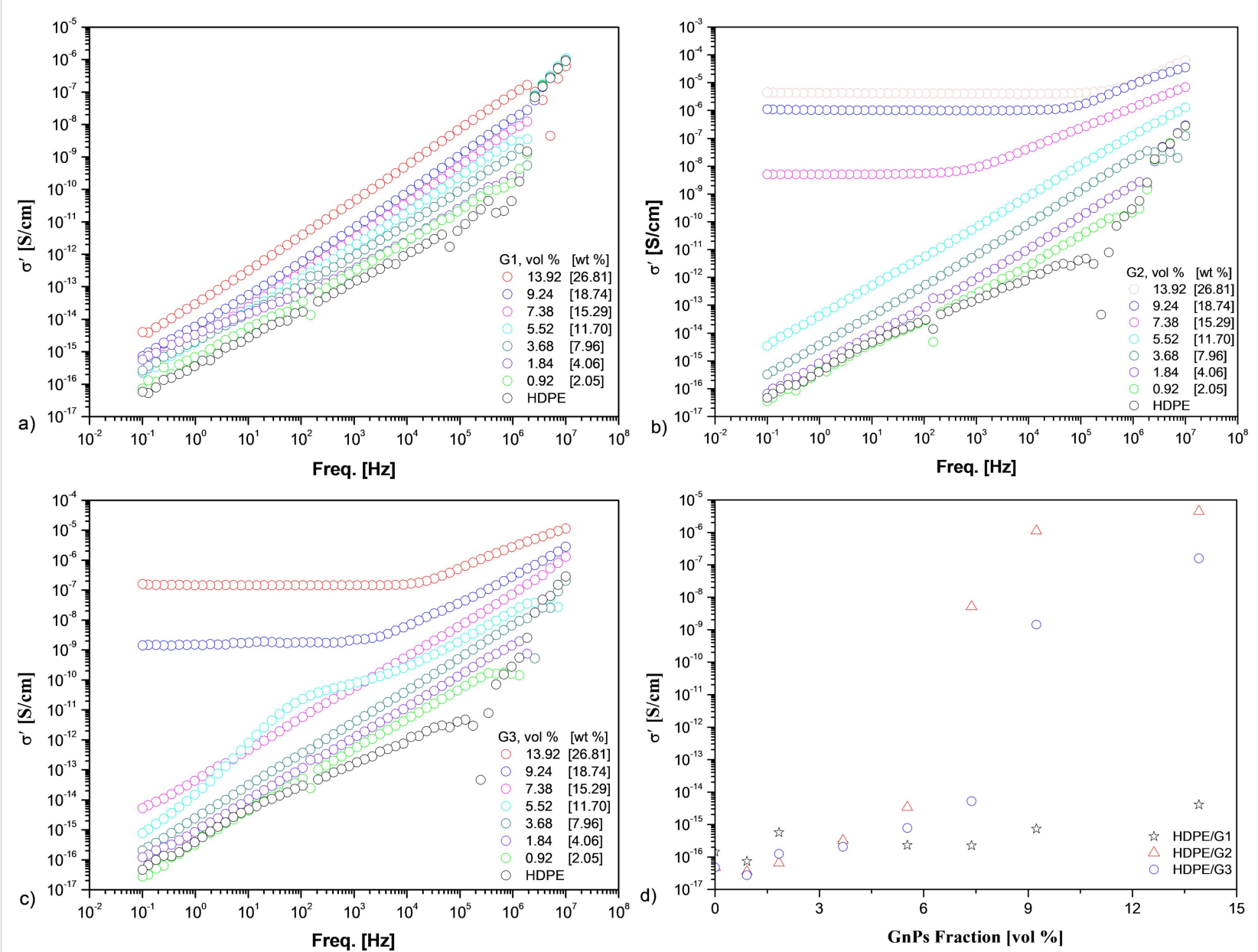

Figure 4: Real part of AC electrical conductivity vs frequency for a) HDPE/G1, b) HDPE/G2, and c) HDPE/G3 nanocomposites as well as d) $\sigma^{\prime}$ AC at $0.1 \mathrm{~Hz}$ vs vol \% of GnP for the HDPE/GnP nanocomposites.

However, the aspect ratio was not the only important parameter. As described by Horny and co-workers [29], for a given lateral size, an optimal thickness exists that gives the highest thermal conductivity. It could be assumed that this is also valid for electrical conductivity. Here, the optimum value for thickness seemed to be closer to 5-8 $\mathrm{nm}$ than 50-100 $\mathrm{nm}$ when comparing GnPs with the same lateral size (i.e., G1 and G3) because the lower percolation threshold was observed for G3 (Figure 4). It is worthwhile to mention that the efficiency of G2 in enhancing the electrical conductivity of HDPE was even better than that of G1 and G3. Finally, compared to GnPs with the same thickness but different lateral sizes, GnPs with larger lateral sizes exhibited a lower percolation threshold and higher enhancement of their electrical conductivity, as they formed a more easily conductive network and a better dispersion. Our results were in agreement with those of Jun and co-workers [8], who also found that the percolation threshold of the PP-based nanocomposites decreased with increasing lateral size of GnPs, while the thermal conductivity of samples increased. However,
Al-Imran and co-workers. [9] and Jiang and Drzal [13] claimed that the percolation threshold values of the nanocomposites was almost the same regardless of GnP size. Additionally, compared in terms of thickness, the nanocomposites with thicker GnPs had a lower electrical conductivity due to a poorer dispersion level, confirming the hypothesis of the existence of an optimum thickness for a given lateral size.

\section{Thermal conductivity}

Thermal diffusivity measurements were performed by the photothermal radiometry (PTR) method, and the thermal conductivity $\left(k=\alpha \cdot \rho \cdot C_{\mathrm{p}}\right)$ of nanocomposites was calculated by combining the experimentally measured thermal diffusivity $(\alpha)$ data, the theoretical specific heat $\left(C_{\mathrm{p}}\right)$, and the density $(\rho)$ values. These theoretical values were determined by mixing law theory. $C_{\mathrm{pm}}$ and $C_{\mathrm{pf}}$ were taken as $1832.9 \mathrm{~J} /(\mathrm{kg} \cdot \mathrm{K})$ [3] and $700 \mathrm{~J} /(\mathrm{kg} \cdot \mathrm{K})[30]$, respectively, and $\rho_{\mathrm{m}}$ and $\rho_{\mathrm{f}}$ were used as $964.9 \mathrm{~kg} / \mathrm{m}^{3}$ [3] and $2186.7 \mathrm{~kg} / \mathrm{m}^{3}$ [31-33], respectively. The subscripts $\mathrm{m}$ and $\mathrm{f}$ referred to the matrix and filler material, re- 
spectively. The results of the relative thermal conductivity measurements are given in Figure 5.

As a reference, the thermal conductivity of pure HDPE is $0.386 \mathrm{~W} / \mathrm{mK}$ [3]. In Figure 5, regardless of the GnP size, the thermal conductivity of the nanocomposites increased linearly with the addition of GnPs due to the high thermal conductivity and large contact area of the GnPs. No thermal percolation threshold was observed for all types of nanocomposites. The thermal conductivity enhancement was stronger for the HDPE/ G2-based nanocomposite than for those with G1 and G3 at any given $\mathrm{GnP}$ concentration. For example, with a GnP content of $13.92 \mathrm{vol} \%$, the thermal conductivity of the HDPE/G2 nanocomposite was $0.729 \mathrm{~W} / \mathrm{mK}$, while for the HDPE/G1 and HDPE/G3 nanocomposites, it was enhanced up to $0.521 \mathrm{~W} / \mathrm{mK}$ and $0.625 \mathrm{~W} / \mathrm{mK}$, respectively. Therefore, G2 demonstrated a better enhancement of $89 \%$ compared to pure HDPE, while G1 and $\mathrm{G} 3$ showed improvements of $35 \%$ and $62 \%$, respectively. Moreover, despite the high intrinsic thermal conductivity of GnPs, the thermal conductivities of the HDPE/GnP nanocomposites increased moderately. The lower than expected thermal conductivity enhancement was mainly ascribed to the high interfacial thermal boundary resistance (TBR) between the HDPE matrix and the GnP fillers. TBR is a physical parameter causing lower thermal conductivity by hindering phonon transfer between the HDPE matrix and the GnPs fillers $[21,34,35]$.

Furthermore, GnPs with larger lateral size showed a larger enhancement of the thermal conductivity. A similar lateral-size effect of GnPs was also observed in earlier studies [13,18,21]. One reason was that the fillers could more easily contact each other to create a more conductive network within the nanocomposites, resulting in a higher thermal conductivity $[13,21,36]$. Another reason was that a small lateral size increased phonon scattering at the matrix-bonded interface, resulting in a lower thermal conductivity of the nanocomposites [21]. Additionally, for the same lateral size, G3 showed a slight enhancement of the thermal conductivity compared to G1 (the enhancement became more effective at 13.92 vol \% loading). Based on the obtained results, it is suggested that, for a given lateral size, the maximum thermal conductivity is obtained at the optimum thickness of GnPs. For a fixed lateral size $(5 \mu \mathrm{m})$, the optimum thickness was approximately 5-8 nm over 50-100 nm. The reason may have been that thinner GnPs could couple well to the HDPE matrix and form a more effective thermal conductive network. Hovewer, Figure 5 displays that the thermal conductivity of HDPE/G3 nanocomposites slightly decreased up to 1.84 vol \% GnPs loading. The explanation is that G3 tended to aggregate, resulting in a decreased contact area between HDPE and G3, as mentioned by Huang and co-workers [5].

Subsequently, the enhancement of the thermal conductivity of the HDPE-based nanocomposites could be increased by optimizing the lateral size and thickness of GnPs at a fixed GnP concentration. Based on these results, the lateral size of GnPs was a more important parameter than the thickness of GnPs in terms of thermal conductivity enhancement. The thermal conductivity of the nanocomposites with a larger lateral size

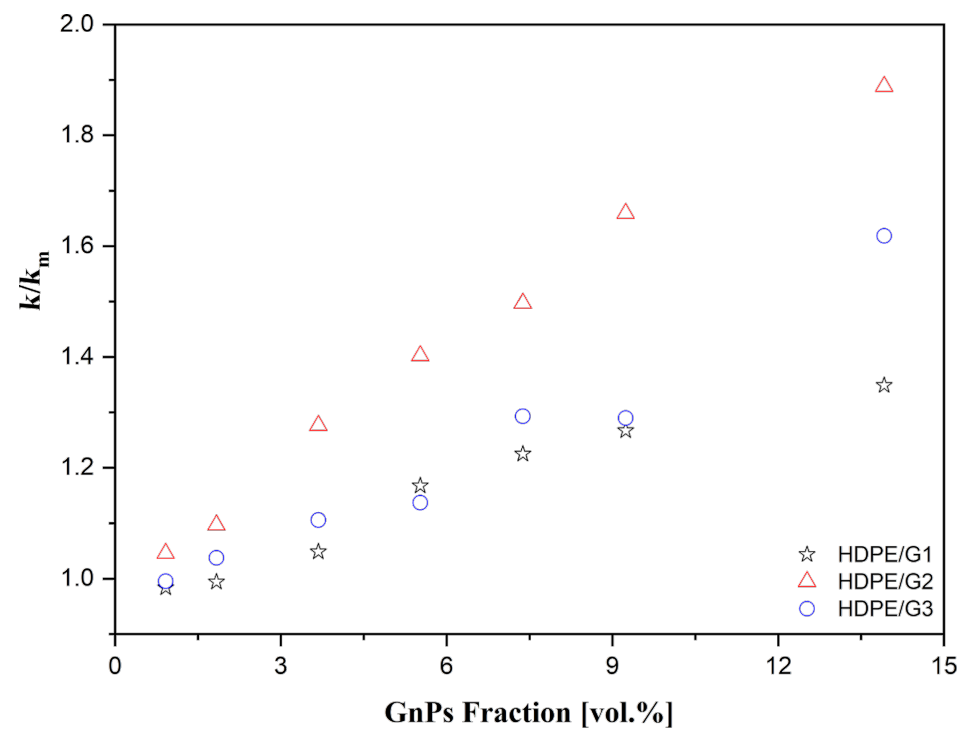

Figure 5: The relative thermal conductivity values of HDPE-based nanocomposites with $\mathrm{G} 1$, G2, and G3 fillers $\left(k_{\mathrm{m}}\right.$ was equal to the thermal conductivity of the matrix) 
could be further increased by forming a more effective thermal conductive pathway and reducing phonon scattering at the matrix/filler interface. In addition, to obtain the same thermal conductivity enhancement, larger amounts of thicker GnPs were required rather than thinner GnPs. Consequently, as previously mentioned, it was clear that the highest enhancement of the electrical and thermal properties was achieved by HDPE/G2 nanocomposites. The reason may have been that $\mathrm{G} 2$ could establish a more effective conducting network and cause an increased filler contact. In addition, G2, with higher lateral size, exhibited a better phonon diffusion mechanism along the conductive network.

\section{Mechanical properties}

Following the electrical and thermal characterization, Figure 6 shows the relative Young's moduli of the pure HDPE and HDPE/GnP nanocomposites. The Young's moduli of the nanocomposites increased with increasing GnP loading, regardless of the GnP size. This may have been due to the extraordinary Young's moduli of GnPs, their high aspect ratio, good dispersion, and good interfacial adhesion between GnPs and HDPE, which restricted the polymer chain mobility under the load [6,37]. The influence of GnP loadings increased the crosslink ratio and hindered the molecular motion of the matrix [6]. When the GnP loading was 13.92 vol \%, the enhancements of the Young's moduli of the HDPE/G1, HDPE/G2, and HDPE/ G3 nanocomposites were $114.36 \%, 168.21 \%$, and $184.58 \%$, respectively. As seen in Figure 6a, the highest Young's modulus was achieved by the HDPE/G3 nanocomposite, with an increment of up to $2.37 \mathrm{GPa}$. It can be seen that the Young's modulus of the HDPE/G1 nanocomposite was the lowest, while the value of the Young's modulus of the HDPE/G3 nanocomposite was the highest.

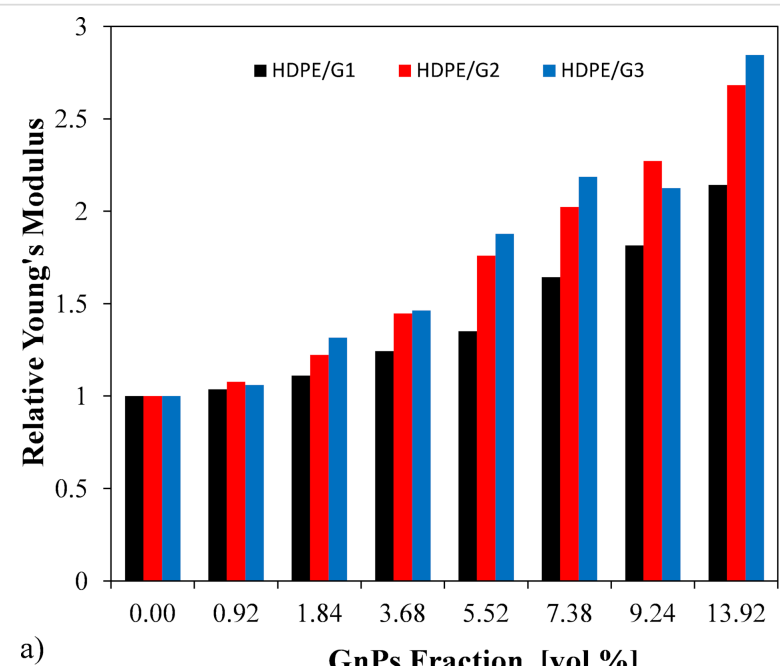

a)

GnPs Fraction [vol \%]
First, the tensile strength of the HDPE/G2 and HDPE/G3 nanocomposites decreases with increasing $\mathrm{GnP}$ loading in the range of $0-1.87 \mathrm{vol} \%$, while the HDPE/G3 nanocomposites showed a decrement in tensile strength in the range of 1.87-5.52 vol \% of GnPs. These decrements were $17.68 \%$ for the HDPE/G2 nanocomposite and $15.53 \%$ for the HDPE/G3 nanocomposite using $1.87 \mathrm{vol} \% \mathrm{GnP}$ filler. The tensile strength depends on the filler content in a complex way [38]. The presence of filler can suppress the drawability of the polymer chains and increase the concentration of defects, which can then result in a decreased tensile strength. On the other hand, the filler can reinforce the polymer matrix, and this reinforcing effect becomes more obvious at higher concentrations ( $\geq 7 \mathrm{vol} \%)$. The nonlinear behavior of the tensile strength is then a consequence of these effects. With 37.27 MPa, the tensile strength of the HDPE/G2 nanocomposite seemed to be the highest among all HDPE/ GnPs, and demonstrated a $7.47 \%$ enhancement compared to HDPE. On the other hand, the HDPE/G1 nanocomposite demonstrated a decrease of $6.33 \%$ in tensile strength, while the HDPE/G3 nanocomposite displayed an increase of $0.83 \%$ compared to pure HDPE.

It was found that G3, with a smaller size and thickness (larger aspect ratio and surface area), showed an effective enhancement of the Young's moduli of the nanocomposites owing to the fact that a larger surface area provided a more efficient stress transfer between GnPs and the HDPE matrix, while G2, with a larger size and thickness, demonstrated an effective improvement of the tensile strength of the nanocomposites because G2 achieved a better dispersion with less agglomeration, as seen in SEM images. According to the obtained results, the dispersion of GnPs in the HDPE matrix was a more important parameter for the tensile stress than others; however, the

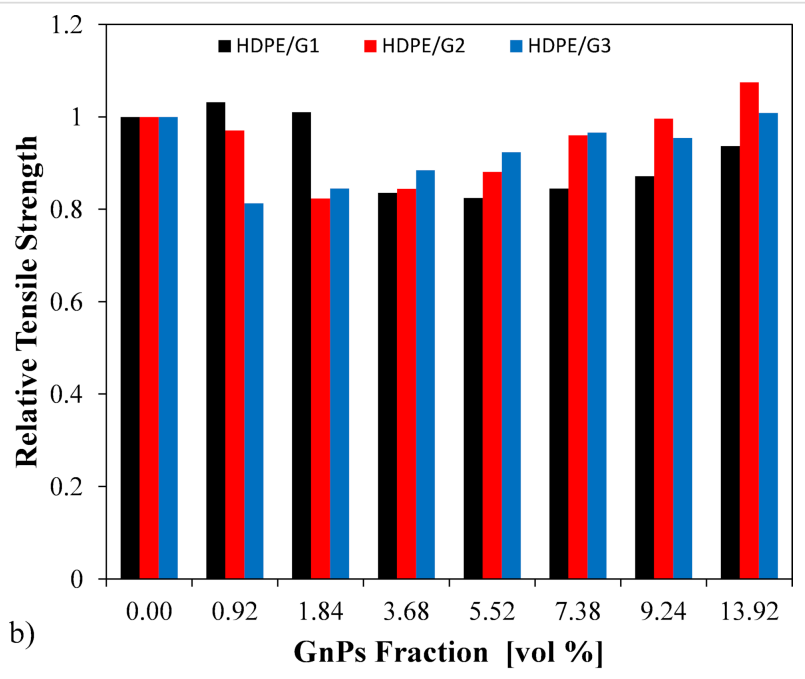

Figure 6: Relative mechanical properties of the HDPE/GnP nanocomposites: a) Young's moduli and b) tensile strengths. 
surface area of GnPs was a more critical factor. In the literature, a similar type of observation was made by Liang et al. [16,17] and Jun and co-workers [8] where it was reported that GnPs with smaller lateral sizes were more favorable for enhancing the mechanical properties of PP-based nanocomposites.

\section{Thermal properties}

The crystallization temperatures $\left(T_{\mathrm{c}}\right)$, melting temperatures $\left(T_{\mathrm{m}}\right)$, heats of fusion $\left(\Delta H_{\mathrm{f}}\right)$, and crystallinities $\left(X_{\mathrm{c}}\right)$ of pure HDPE and the HDPE/GnP nanocomposites are given in Table 2. $T_{\mathrm{c}}$ for pure HDPE was found to be $116.30^{\circ} \mathrm{C}$, whereas for all HDPE/GnP nanocomposites, $T_{\mathrm{c}}$ increased by approximately $5{ }^{\circ} \mathrm{C}$ at 13.92 vol $\% \mathrm{GnP}$ content due to the nucleation effect of the GnPs. It was clearly seen that $T_{\mathrm{m}}$ of all $\mathrm{HDPE} / \mathrm{GnP}$ nanocomposites ranged from $130.43{ }^{\circ} \mathrm{C}$ to $132.17{ }^{\circ} \mathrm{C}$, which almost equaled that of pure HDPE $\left(130.09^{\circ} \mathrm{C}\right)$. For all samples, $X_{\mathrm{c}}$ first increased and then decreased with increasing $\mathrm{GnP}$ content. This was due to a compromise between the nucleating and retarding effects of GnPs on the HDPE matrix, as mentioned by Jiang and Drzal [13]. It was clear that $\Delta H_{\mathrm{f}}$ of all HDPE/GnP nanocomposites decreased by approximately $25 \%$ to a minimum value with $13.92 \mathrm{vol} \% \mathrm{GnP}$ loading. The crystallinity degree of the pure HDPE was $\approx 70 \%$ and increased up to $\approx 71 \%$ with 13.92 vol $\% \mathrm{G} 1$ and G2, respectively, and up to $\approx 72 \%$ with $13.92 \mathrm{vol} \% \mathrm{G} 3$. This increase was relatively inconsiderable considering the GnP content added to the HDPE matrix. These results clearly demonstrate that while there was a slight effect of the GnP loading on $T_{\mathrm{m}}$ and $X_{\mathrm{c}}$, a significant effect on $T_{\mathrm{c}}$ and $\Delta H_{\mathrm{f}}$ was observed. It could be observed that the size of GnPs induced little difference in these properties of the HDPE-based nanocomposites.

The parameters for the thermal stabilities predicted by TGA are given in Table 3. TGA curves of the samples are shown in Figure 7. Figure 7 shows that pure HDPE and the three HDPE/ GnP nanocomposites all demonstrated a single-step thermal decomposition behavior between almost $440{ }^{\circ} \mathrm{C}$ and $500{ }^{\circ} \mathrm{C}$, indicating that the increment of the GnPs could not affect the thermal decomposition behavior of the pure matrix. It was clear that the HDPE/GnP nanocomposites demonstrated better thermal stability than pure HDPE. The thermal stability of the HDPEbased nanocomposites decreased at a low volume fraction of GnP. This may have been due to agglomeration of the GnPs in the polymer matrix [8]. The agglomeration of the GnPs may have increased the molecular mobility and decreased the thermal stability of the polymer nanocomposites [39]. The thermal stability of the nanocomposites was enhanced by increasing the content of all three GnPs. This was attributed to the high thermal stability of the GnPs, the GnPs' shielding effect on the combustion gas diffusion into and out of the polymer during its thermal decomposition [18], the barrier effect of the GnPs, the removal of free radicals, which started polymer decomposition, and uniform dispersion of the GnPs [8].

Another reason was the hindering influence of the GnP layers on the diffusion of small gaseous molecules across the HDPEbased nanocomposites [40]. Generally, $T_{5 \%}$ (5\% sample weight loss) was defined as the onset degradation temperature [17].

\begin{tabular}{|c|c|c|c|c|c|c|c|c|c|c|c|c|}
\hline \multirow{2}{*}{$\begin{array}{l}\text { GNP } \\
\text { (vol \%) }\end{array}$} & \multicolumn{3}{|c|}{$T_{\mathrm{m}}\left({ }^{\circ} \mathrm{C}\right)$} & \multicolumn{3}{|c|}{$T_{\mathrm{C}}\left({ }^{\circ} \mathrm{C}\right)$} & \multicolumn{3}{|c|}{$\Delta H_{\mathrm{f}}(\mathrm{J} / \mathrm{g})$} & \multicolumn{3}{|c|}{$X_{\mathrm{c}}(\%)$} \\
\hline & $\begin{array}{l}\text { HDPE/ } \\
\text { G1 }\end{array}$ & $\begin{array}{l}\text { HDPE/ } \\
\text { G2 }\end{array}$ & $\begin{array}{l}\text { HDPE/ } \\
\text { G3 }\end{array}$ & $\begin{array}{l}\text { HDPE/ } \\
\text { G1 }\end{array}$ & $\begin{array}{l}\text { HDPE/ } \\
\text { G2 }\end{array}$ & $\begin{array}{l}\text { HDPE/ } \\
\text { G3 }\end{array}$ & $\begin{array}{l}\text { HDPE/ } \\
\text { G1 }\end{array}$ & $\begin{array}{l}\text { HDPE/ } \\
\text { G2 }\end{array}$ & $\begin{array}{l}\text { HDPE/ } \\
\text { G3 }\end{array}$ & $\begin{array}{l}\text { HDPE/ } \\
\text { G1 }\end{array}$ & $\begin{array}{l}\text { HDPE/ } \\
\text { G2 }\end{array}$ & $\begin{array}{l}\text { HDPE/ } \\
\text { G3 }\end{array}$ \\
\hline 0 & 130.09 & 130.09 & 130.09 & 116.30 & 116.30 & 116.30 & 205.80 & 205.80 & 205.80 & 70.24 & 70.24 & 70.24 \\
\hline 1.84 & 131.82 & 132.17 & 132.01 & 117.66 & 117.31 & 117.33 & 200.60 & 205.20 & 204.20 & 71.36 & 73.00 & 72.64 \\
\hline 5.52 & 130.89 & 131.63 & 132.05 & 118.67 & 119.97 & 118.47 & 189.10 & 186.40 & 189.50 & 73.10 & 72.05 & 73.25 \\
\hline 9.24 & 130.43 & 131.69 & 131.38 & 119.56 & 120.63 & 119.83 & 173.70 & 172.20 & 174.50 & 72.96 & 72.33 & 73.24 \\
\hline 13.92 & 131.80 & 131.18 & 131.39 & 121.02 & 121.57 & 120.06 & 153.10 & 153.10 & 153.90 & 71.39 & 71.39 & 71.77 \\
\hline
\end{tabular}

\begin{tabular}{|c|c|c|c|c|c|c|c|c|c|c|c|c|}
\hline \multirow{2}{*}{$\begin{array}{l}\text { GNP } \\
\text { (vol \%) }\end{array}$} & \multicolumn{3}{|c|}{$T_{5 \%}\left({ }^{\circ} \mathrm{C}\right)$} & \multicolumn{3}{|c|}{$T_{50 \%}\left({ }^{\circ} \mathrm{C}\right)$} & \multicolumn{3}{|c|}{$T_{\text {deg }}\left({ }^{\circ} \mathrm{C}\right)$} & \multicolumn{3}{|c|}{ residual mass (\%) } \\
\hline & $\begin{array}{l}\text { HDPE/ } \\
\text { G1 }\end{array}$ & $\begin{array}{l}\text { HDPE/ } \\
\text { G2 }\end{array}$ & $\begin{array}{l}\text { HDPE/ } \\
\text { G3 }\end{array}$ & $\begin{array}{l}\text { HDPE/ } \\
\text { G1 }\end{array}$ & $\begin{array}{l}\text { HDPE/ } \\
\text { G2 }\end{array}$ & $\begin{array}{l}\text { HDPE/ } \\
\text { G3 }\end{array}$ & $\begin{array}{l}\text { HDPE/ } \\
\text { G1 }\end{array}$ & $\begin{array}{l}\text { HDPE/ } \\
\text { G2 }\end{array}$ & $\begin{array}{l}\text { HDPE/ } \\
\text { G3 }\end{array}$ & $\begin{array}{l}\text { HDPE/ } \\
\text { G1 }\end{array}$ & $\begin{array}{l}\text { HDPE/ } \\
\text { G2 }\end{array}$ & $\begin{array}{l}\text { HDPE/ } \\
\text { G3 }\end{array}$ \\
\hline 0 & 440.77 & 440.77 & 440.77 & 474.44 & 474.44 & 474.44 & 478.79 & 478.79 & 478.79 & 0.84 & 0.84 & 0.84 \\
\hline 1.84 & 421.66 & 425.42 & 415.48 & 475.11 & 476.86 & 478.31 & 479.07 & 480.62 & 481.45 & 3.88 & 1.53 & 3.09 \\
\hline 5.52 & 449.97 & 456.34 & 456.46 & 481.68 & 485.53 & 485.06 & 483.55 & 487.62 & 486.63 & 13.19 & 13.52 & 11.68 \\
\hline 9.24 & 456.05 & 461.50 & 456.16 & 486.82 & 488.91 & 487.37 & 487.31 & 489.92 & 488.27 & 19.58 & 19.02 & 19.24 \\
\hline 13.92 & 461.05 & 459.45 & 457.16 & 490.19 & 490.99 & 489.64 & 489.52 & 489.54 & 488.64 & 27.44 & 27.31 & 26.75 \\
\hline
\end{tabular}



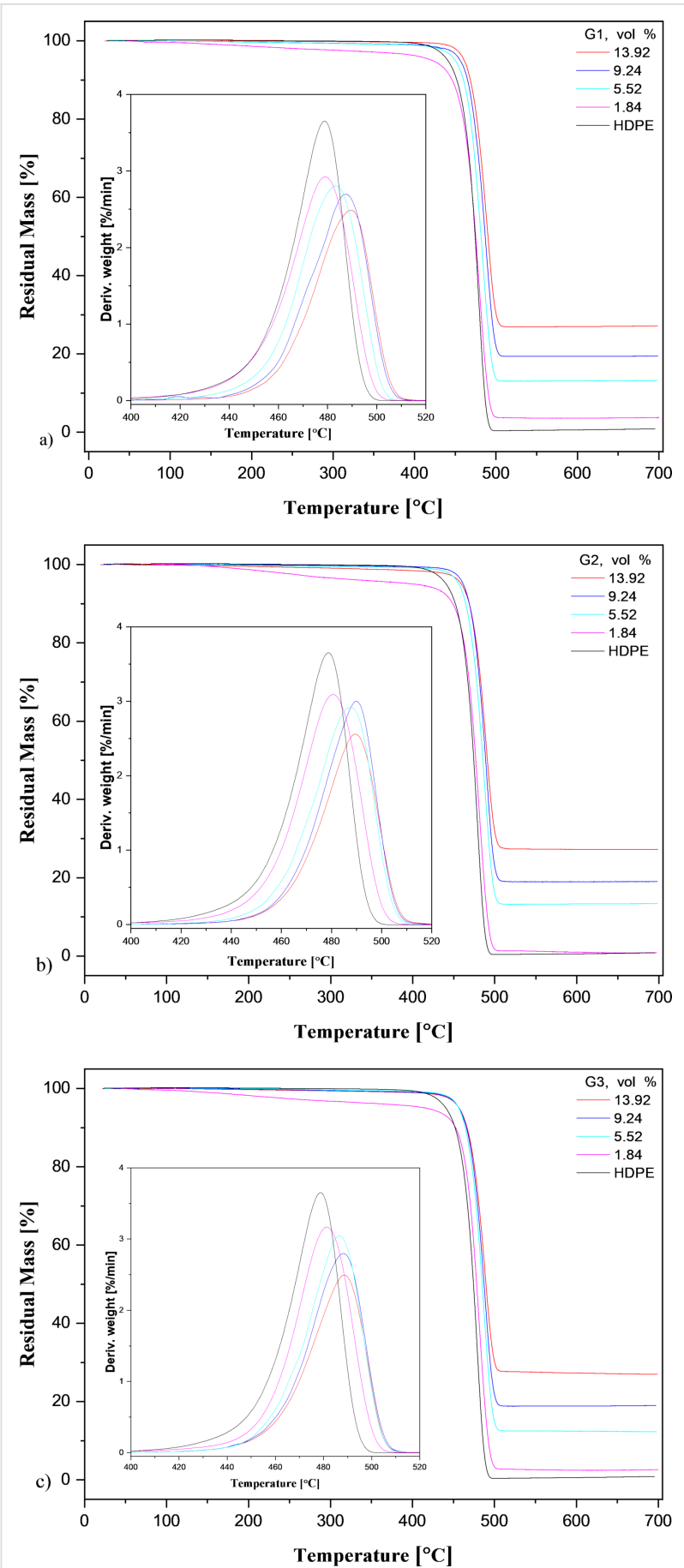

Figure 7: TGA thermographs of the HDPE/GnP nanocomposites with a) G1, b) G2, and c) G3 filler. The insets show derivative thermogravimetric (DTG) curves.

The $T_{5 \%}$ value of pure HDPE was $440.77^{\circ} \mathrm{C}$, while this value increased to $461.05{ }^{\circ} \mathrm{C}, 459.45^{\circ} \mathrm{C}$, and $457.16^{\circ} \mathrm{C}$, respectively, for the HDPE/G1, HDPE/G2, and HDPE/G3 nanocomposites. This showed that the GnPs had a positive influence on the thermal stability of HDPE-based nanocomposites [40]. For three types of HDPE/GnP nanocomposites, $T_{\text {deg }}$ (maximum weight loss) increased by approximately $11^{\circ} \mathrm{C}$ compared to the pure HDPE matrix $\left(478.79{ }^{\circ} \mathrm{C}\right)$. The addition of GnPs increased this temperature; however, the size and concentration of the GnPs did not greatly influence $T_{\text {deg }}$. The residual mass of the HDPEbased nanocomposites increased with increasing GnP loading, which was attributed to the existence of a carbon net structure in the HDPE/GnP nanocomposites [40] because the initial thermal degradation temperature of the GnPs was above $600{ }^{\circ} \mathrm{C}$ [15]. However, the GnP size did not have a significant effect on $T_{50 \%}, T_{\mathrm{deg}}$, and the residual mass of the HDPE-based nanocomposites with GnPs, rather, it only affected $T_{5 \%}$.

\section{Conclusion}

The HDPE-based nanocomposites with three types of GnPs (G1, G2, and G3), having different thicknesses and lateral sizes, were prepared by a melt mixing method and compression molding. The size effects of the GnPs on the morphological, thermal, electrical, and mechanical properties of the composites was studied. The small differences in the GnPs' surfaces' chemical composition were detected by XPS, and the highest amount of oxygen that was found was 2.6 atom $\%$ for G1. FTIR and XRD findings showed that the addition and size of GnPs led to slight differences in the FTIR spectra of the nanocomposites compared to that of pure HDPE, while the addition of GnPs affected the reflection peaks and peak intensities. Based on SEM images, all GnPs showed uniform and random dispersion in the HDPE matrix. In particular, G2 displayed more GnP pathways, while G3 displayed a worse distribution than the other two. The lateral size of the GnPs was a more critical parameter for thermal and electrical conductivity enhancements of the nanocomposites than their thickness. Among all HDPE/GnP nanocomposites, the thermal and electrical conductivities of the HDPE/G2 nanocomposite were the highest, with $0.729 \mathrm{~W} / \mathrm{mK}$ and $4.46 \times 10^{-6} \mathrm{~S} / \mathrm{cm}$, corresponding to $\approx 89 \%$ and $\approx 11$ orders of magnitude enhancement, respectively, compared to pure HDPE. As examined in terms of thickness, for a fixed lateral size, an optimal thickness was required to achieve the highest electrical and thermal conductivities. Additionally, the percolation threshold varied significantly with the size of the GnPs. G2 showed the lowest percolation threshold, and the nanocomposites with thinner GnPs exhibited lower percolation and higher electrical conductivity compared to those with thicker GnPs. Additionally, it was found that G1, with smaller lateral size and larger thickness (and the lowest aspect ratio and surface area), showed the lowest enhancement of the Young's modulus and tensile strength due to worse distribution in the HDPE matrix and a less effective stress transfer between HDPE and GnPs. While a slight size effect of GnPs on $T_{\mathrm{m}}, T_{\mathrm{c}}, \Delta H_{\mathrm{f}}$, and $X_{\mathrm{c}}$ of the nanocomposites was observed, the addition of GnPs influenced $\Delta H_{\mathrm{f}}$ and $T_{\mathrm{c}}$; however, it did not affect $T_{\mathrm{m}}$ and $X_{\mathrm{c}}$. In addition, the thermal stability of the nanocomposites increased with in- 
creasing GnP content; however, the size of the GnPs only influenced $T_{5 \%}$.

In summary, considering all the experimental measurements, G2 (having larger lateral size) seemed to be the most favorable type of $\mathrm{GnP}$ to achieve the best enhancement of nanocomposite properties.

\section{Experimental Materials}

HDPE (LITEN FB 75, Unipetrol) with a density of $948 \mathrm{~kg} / \mathrm{m}^{3}$ and a melt flow rate of $0.45 \mathrm{~g} / 10 \mathrm{~min}\left(190{ }^{\circ} \mathrm{C}, 5 \mathrm{~kg}\right)$ was used as matrix material. Three different sizes of GnPs with trademark iGP (diameter $(D) \approx 5 \mu \mathrm{m}$, thickness $(t)=50-100 \mathrm{~nm}$, aspect ratio $(\mathrm{AR})=50-100$, surface area $\left.(\mathrm{SA})=13 \mathrm{~m}^{2} / \mathrm{g}\right)$, iGP $\left(D \approx 44 \mu \mathrm{m}, t=50-100 \mathrm{~nm}, \mathrm{AR}=440-880, \mathrm{SA}=40 \mathrm{~m}^{2} / \mathrm{g}\right)$, and $\operatorname{iGP} 2(D \approx 5 \mu \mathrm{m}, t=5-8 \mathrm{~nm}, \mathrm{AR}=625-1000$, $\mathrm{SA}=120-150 \mathrm{~m}^{2} / \mathrm{g}$ ) were provided by Grafen Chemical Industries Co. and used as filler materials to investigate the size effect of GnPs on the properties of the HDPE/GnP nanocomposites. The GnPs with trademark iGP $(D \approx 5 \mu \mathrm{m})$, iGP $(D \approx 44 \mu \mathrm{m})$, and iGP2 $(D \approx 5 \mu \mathrm{m})$ were labelled G1, G2, and G3. All GNPs were used as supplied by the producer without any purification or functionalization process. The physical properties of the GNPs are shown in Table 4.

Table 4: Sizes of GnPs used in this study.
\begin{tabular}{lllll} 
GnPs & lateral size $(D, \mu \mathrm{m})$ & $t(\mathrm{~nm})$ & $\mathrm{AR}$ & $\mathrm{SA}\left(\mathrm{m}^{2} / \mathrm{g}\right)$ \\
\hline $\mathrm{G} 1$ & $\approx 5$ & $50-100$ & $50-100$ & 13 \\
$\mathrm{G} 2$ & $\approx 44$ & $50-100$ & $440-880$ & 44 \\
$\mathrm{G} 3$ & $\approx 5$ & $5-8$ & $635-1000$ & $120-150$
\end{tabular}

\section{Preparation of polymer nanocomposites}

HDPE/GnP nanocomposites were produced by a melt mixing method using various amounts of filler up to $13.92 \mathrm{vol} \%$ (26.81 wt \%) of GnP content. The volume fractions were calculated using the weight fraction of GnPs and densities of the pure constituents [1,3]. The HDPE-based nanocomposites were prepared in a Brabedender Plasticorder PLE 331 apparatus with a $30 \mathrm{~mL}$ mixing chamber at $160{ }^{\circ} \mathrm{C}$ for $15 \mathrm{~min}$ at $35 \mathrm{rpm}$. The samples for measurements were prepared by compression molding using a hot press (Fontijne 200, Fontijne Presses) at $180^{\circ} \mathrm{C}$ without pressure for $2 \mathrm{~min}$ and under pressure (40 kPA) for $3 \mathrm{~min}$, then solidified by air cooling.

\section{Characterization}

$\mathrm{X}$-ray photoelectron spectroscopy (K-alpha X-ray photoelectron spectrometer (XPS) system, Thermo Fisher Scientific) analysis was used to characterize the surface properties of the
GnPs. The GnP and nanocomposite morphologies were investigated by SEM (XL 30S FEG electron microscope, Philips). The nanocomposite microstructures were examined at a cryofractured surface in liquid nitrogen, and then coated with a thin layer of gold. XRD analyses (X'Pert PRO, Philips) were performed to determine the overall phase and crystalline structure of the samples. The XRD patterns were recorded at $5-85^{\circ}$, with a scanning speed of $0.03^{\circ} \mathrm{s}$. FTIR measurements were carried out with a Thermo Fisher Scientific iS10 infrared spectrometer in the range of $4000-650 \mathrm{~cm}^{-1}$ at room temperature.

Broadband dielectric spectroscopy (BDS) measurements were conducted using a Novocontrol Concept 40 instrument with an Alpha dielectric spectrometer supplied by Novocontrol Technologies GmbH. A BDS-1200 parallel-plate capacitor with two gold-plated electrodes was used as a test cell for the samples and provided by Novocontrol Technologies. The diameter and thickness of the samples was $20 \mathrm{~mm}$ and $0.5 \mathrm{~mm}$, respectively. All measurements were carried out in the $0.1 \mathrm{~Hz}-1 \mathrm{MHz}$ frequency range at room temperature.

The thermal diffusivity of the samples was measured by the PTR technique, which is a nondestructive characterization method based on the detection of an IR signal, called the photothermal signal, emitted after a change of the sample's temperature [41]. The heating is achieved by a frequencymodulated laser beam (DPSS, Dream Lasers Technol. Co., model SDL-532-300T) with $300 \mathrm{~mW}$ at $532 \mathrm{~nm}$ wavelength and a diameter of $0.6 \mathrm{~mm}$ at 1/e. The IR radiations linked to the fast conversion of a fraction of the absorbed optical energy into heat were collected by a suitable optic (Au-coated mirrors, Edmund Optics) and focused on an IR photodetector ( $\mathrm{HgCdTe}$ photoconductive detector, Kolmar Technologies, KMPV 11-1J1/DC). Afterwards, a lock-in amplifier (Stanford Research Systems SR865) output the amplitude and phase of the detector's electrical signal proportional to the variation of the sample surface temperature, which depended on its thermophysical properties. A more detailed description of the setup used can be found elsewhere [42]. Using this PTR setup, different types of material (nanocomposites [3], organic [43-45], irradiated [46], metal-semiconductor couples [42,47], etc.) can be thermally characterized to determine thermophysical properties, such as the thermal diffusivity and thermal effusivity. At lower frequencies, the measurements are subject to 3D effects and necessitate a change in the laser beam shape. At low frequencies, a flat top (FT) optics grouping consisting of a diffuser/ beam-shaper (ED1-C20, diameter 1", 20, Circle Pattern Diffuser, Thorlabs) and two lenses (one to collect the large diffused beam and another to converge it on the sample) was used. Using this configuration, the shape of the heating spot was circular, and the illumination was uniform on the sample's 
surface. The heating was therefore considered $1 \mathrm{D}$, and a $1 \mathrm{D}$ thermal characterization of the HDPE samples could be applied by analyzing the amplitude and phase of the PTR signal using a 1D quadrupole-based model $[48,49]$. This modeling was used by a Gauss-Newton algorithm to simultaneously adjust the experimental amplitude and phase of the PTR signal analyzed by the lock-in amplifier to extract the thermal diffusivity and optical absorption coefficient of the studied samples.

The tensile tests were conducted using an Instron 4301 tensile test machine at a crosshead speed of $10 \mathrm{~mm} / \mathrm{min}$ at room temperature, according to ASTM D638. The samples were cut in dog-bone shapes with a thickness of $1 \mathrm{~mm}$, a width of $4 \mathrm{~mm}$, and a gauge length of $30 \mathrm{~mm}$ by a pneumatic press (APK $4 \mathrm{~L}$, Tinius Olsen LTD). The mean values of seven tests were reported for each sample.

Thermogravimetric analysis (TGA) of the samples was performed using a Q500 system from TA Company. TGA was carried out at a heating rate of $10{ }^{\circ} \mathrm{C} / \mathrm{min}$ from room temperature to $700{ }^{\circ} \mathrm{C}$ under a nitrogen atmosphere.

Differential scanning calorimetry (DSC) analysis was performed using a modulated differential scanning calorimeter (Q200 series MDSC, TA instruments) under a nitrogen atmosphere in the $-10{ }^{\circ} \mathrm{C}-200{ }^{\circ} \mathrm{C}$ range. Two heating cycles were performed for each sample. The samples were initially heated from $-10{ }^{\circ} \mathrm{C}-200{ }^{\circ} \mathrm{C}$ at $10{ }^{\circ} \mathrm{C} / \mathrm{min}^{-1}$ and held at $200{ }^{\circ} \mathrm{C}$ for $1 \mathrm{~min}$ to eliminate the thermal history of the samples. Then, they were cooled to $-10{ }^{\circ} \mathrm{C}$ at the same rate and held for $1 \mathrm{~min}$ at this temperature. Finally, the samples were reheated to $200{ }^{\circ} \mathrm{C}$ in the MDSC mode, with a temperature oscillation of $1.326{ }^{\circ} \mathrm{C}$ amplitude, a modulating period $(P)$ of $100 \mathrm{~s}$, and a heating rate of $5{ }^{\circ} \mathrm{C} / \mathrm{min}$. The degree of crystallinity $\left(X_{\mathrm{c}}\right)$ of the samples was determined through Equation 1:

$$
X_{c}=\Delta H \times 100 /\left(\Delta H_{0} \times(1-\varphi)\right)
$$

where $\Delta H$ was the heat of fusion of the sample, $\Delta H_{0}=293 \mathrm{~J} / \mathrm{g}$ was the heat of fusion for $100 \%$ crystalline HDPE [50], and $\varphi$ referred to the weight fraction of the filler in each sample.

\section{Supporting Information}

\section{Supporting Information File 1}

FTIR spectroscopy and XRD patterns of HDPE/GnP nanocomposites with various concentrations of GnPs. [https://www.beilstein-journals.org/bjnano/content/ supplementary/2190-4286-11-14-S1.pdf]

\section{Acknowledgements}

G.H., N.H., and M.C. would like to acknowledge the help of the Grand Est region in France.

\section{Funding}

This work was partially supported by the Science Grant Agency VEGA, project no. 2/0010/18, and 2/0093/16 (Slovakia).

\section{ORCID ${ }^{\circledR}$ iDs}

Tuba Evgin - https://orcid.org/0000-0002-8245-3075 Alpaslan Turgut - https://orcid.org/0000-0003-1114-589X Georges Hamaoui - https://orcid.org/0000-0001-8451-3986 Zdenko Spitalsky - https://orcid.org/0000-0003-2589-9035 Nicolas Horny - https://orcid.org/0000-0003-1633-7989 Maria Omastova - https://orcid.org/0000-0003-0210-5861

\section{References}

1. Chirtoc, M.; Horny, N.; Tavman, I.; Turgut, A.; Kökey, I.; Omastová, M. Int. J. Therm. Sci. 2012, 62, 50-55. doi:10.1016/j.jthermalsci.2012.02.015

2. Mohan, V. B.; Lau, K.-t.; Hui, D.; Bhattacharyya, D. Composites, Part B 2018, 142, 200-220. doi:10.1016/j.compositesb.2018.01.013

3. Evgin, T.; Koca, H. D.; Horny, N.; Turgut, A.; Tavman, I. H.; Chirtoc, M.; Omastová, M.; Novak, I. Composites, Part A 2016, 82, 208-213. doi:10.1016/j.compositesa.2015.12.013

4. Kumar, A.; Sharma, K.; Dixit, A. R. J. Mater. Sci. 2019, 54, 5992-6026. doi:10.1007/s10853-018-03244-3

5. Huang, C.; Qian, X.; Yang, R. Mater. Sci. Eng., R 2018, 132, 1-22. doi:10.1016/j.mser.2018.06.002

6. Zakaria, M. R.; Abdul Kudus, M. H.; Md. Akil, H.; Mohd Thirmizir, M. Z. Composites, Part B 2017, 119, 57-66. doi:10.1016/j.compositesb.2017.03.023

7. Paszkiewicz, S.; Szymczyk, A.; Špitalský, Z.; Mosnáček, J.; Kwiatkowski, K.; Rosłaniec, Z. Eur. Polym. J. 2014, 50, 69-77. doi:10.1016/j.eurpolymj.2013.10.031

8. Jun, Y.-S.; Um, J. G.; Jiang, G.; Yu, A. eXPRESS Polym. Lett. 2018, 12, 885-897. doi:10.3144/expresspolymlett.2018.76

9. Imran, K. A.; Lou, J.; Shivakumar, K. N. J. Appl. Polym. Sci. 2018, 135, 45833. doi:10.1002/app.45833

10. Chaudhry, A. U.; Mittal, V. Polym. Eng. Sci. 2013, 53, 78-88. doi:10.1002/pen.23241

11. Kim, H. S.; Jang, J.-u.; Lee, H.; Kim, S. Y.; Kim, S. H.; Kim, J.; Jung, Y. C.; Yang, B. J. Adv. Eng. Mater. 2018, 20, 1800204. doi:10.1002/adem.201800204

12. Bakir, M.; Meyer, J. L.; Sutrisno, A.; Economy, J.; Jasiuk, I. RSC Adv. 2018, 8, 4946-4954. doi:10.1039/c7ra12506b

13. Jiang, X.; Drzal, L. T. Polym. Compos. 2012, 33, 636-642. doi:10.1002/pc.22187

14. Tarani, E.; Wurm, A.; Schick, C.; Bikiaris, D. N.; Chrissafis, K.; Vourlias, G. Thermochim. Acta 2016, 643, 94-103. doi:10.1016/j.tca.2016.09.018

15. Tarani, E.; Terzopoulou, Z.; Bikiaris, D. N.; Kyratsi, T.; Chrissafis, K.; Vourlias, G. J. Therm. Anal. Calorim. 2017, 129, 1715-1726. doi:10.1007/s10973-017-6342-0

16. Liang, J.-Z.; Du, Q.; Tsui, G. C.-P.; Tang, C.-Y. Composites, Part B 2016, 95, 166-171. doi:10.1016/j.compositesb.2016.04.011 
17. Liang, J.-Z. J. Compos. Mater. 2018, 52, 2443-2450. doi:10.1177/0021998317746478

18. Chatterjee, S.; Nafezarefi, F.; Tai, N. H.; Schlagenhauf, L.; Nüesch, F. A.; Chu, B. T. T. Carbon 2012, 50, 5380-5386. doi:10.1016/j.carbon.2012.07.021

19. Shtein, M.; Nadiv, R.; Buzaglo, M.; Kahil, K.; Regev, O. Chem. Mater. 2015, 27, 2100-2106. doi:10.1021/cm504550e

20. Ravindran, A.; Feng, C.; Huang, S.; Wang, Y.; Zhao, Z.; Yang, J. Polymers (Basel, Switz.) 2018, 10, 477. doi:10.3390/polym10050477

21. Kim, H. S.; Bae, H. S.; Yu, J.; Kim, S. Y. Sci. Rep. 2016, 6, 26825. doi:10.1038/srep26825

22. Sever, K.; Tavman, I. H.; Seki, Y.; Turgut, A.; Omastova, M.; Ozdemir, I. Composites, Part B 2013, 53, 226-233. doi:10.1016/j.compositesb.2013.04.069

23. Wang, Q.; Wang, T.; Wang, J.; Guo, W.; Qian, Z.; Wei, T. Polym. Adv. Technol. 2018, 29, 407-416. doi:10.1002/pat.4129

24. Jouni, M.; Boiteux, G.; Massardier, V. Polym. Adv. Technol. 2013, 24 , 909-915. doi:10.1002/pat.3164

25. Wypych, G. Physical Properties of Fillers and Filled Materials. Handbook of fillers; ChemTec Publishing: Toronto, Canada, 2016; pp 303-371. doi:10.1016/b978-1-895198-91-1.50007-5

26. Al-Saleh, M. H.; Abdul Jawad, S. J. Electron. Mater. 2016, 45 , 3532-3539. doi:10.1007/s11664-016-4505-6

27. Mahmoud, W. E. Eur. Polym. J. 2011, 47, 1534-1540. doi:10.1016/j.eurpolymj.2011.05.011

28. Taherian, R. Compos. Sci. Technol. 2016, 123, 17-31. doi:10.1016/j.compscitech.2015.11.029

29. Horny, N.; Kanake, Y.; Chirtoc, M.; Tighzert, L. Polym. Degrad. Stab. 2016, 127, 105-112. doi:10.1016/j.polymdegradstab.2016.01.006

30. Guan, L.-Z.; Zhao, L.; Wan, Y.-J.; Tang, L.-C. Nanoscale 2018, 10, 14788-14811. doi:10.1039/c8nr03044h

31. Potts, J. R.; Dreyer, D. R.; Bielawski, C. W.; Ruoff, R. S. Polymer 2011, 52, 5-25. doi:10.1016/j.polymer.2010.11.042

32. Araby, S.; Meng, Q.; Zhang, L.; Kang, H.; Majewski, P.; Tang, Y.; Ma, J. Polymer 2014, 55, 201-210. doi:10.1016/j.polymer.2013.11.032

33. Caradonna, A.; Colucci, G.; Giorcelli, M.; Frache, A.; Badini, C. J. Appl. Polym. Sci. 2017, 134, 44814. doi:10.1002/app.44814

34. Shenogin, S.; Xue, L.; Ozisik, R.; Keblinski, P.; Cahill, D. G. J. Appl. Phys. 2004, 95, 8136-8144. doi:10.1063/1.1736328

35. Pietrak, K.; Wisniewski, T. S. J. Power Technol. 2014, 94, 270-285.

36. Jarosinski, L.; Rybak, A.; Gaska, K.; Kmita, G.; Porebska, R. Kapusta, C. Mater. Sci.-Pol. 2017, 35, 382-389. doi:10.1515/msp-2017-0028

37. Yasmin, A.; Luo, J. J.; Daniel, I. M. Compos. Sci. Technol. 2006, 66, 1182-1189. doi:10.1016/j.compscitech.2005.10.014

38. Mičušík, M.; Omastová, M.; Prokeš, J.; Krupa, I. J. Appl. Polym. Sci. 2006, 101, 133-142. doi:10.1002/app.23041

39. Alam, F.; Choosri, M.; Gupta, T. K.; Varadarajan, K. M.; Choi, D.; Kumar, S. Mater. Sci. Eng., B 2019, 241, 82-91. doi:10.1016/j.mseb.2019.02.011

40. Aram, E.; Ehsani, M.; Khonakdar, H. A.; Abdollahi, S. J. Thermoplast. Compos. Mater. 2018, 32, 1176-1189. doi:10.1177/0892705718794776

41. Almond, D. P.; Patel, P. M. Photothermal Science and Techniques; Springer: Amsterdam, Netherlands, 1996.

42. Horny, N.; Chirtoc, M.; Fleming, A.; Hamaoui, G.; Ban, H. Appl. Phys. Lett. 2016, 109, 033103. doi:10.1063/1.4959084

43. Reisdorffer, F.; Garnier, B.; Horny, N.; Renaud, C.; Chirtoc, M.; Nguyen, T.-P. EPJ Web Conf. 2014, 79, 02001. doi:10.1051/epjconf/20137902001
44. Trefon-Radziejewska, D.; Juszczyk, J.; Fleming, A.; Horny, N.; Antoniow, J. S.; Chirtoc, M.; Kaźmierczak-Bałata, A.; Bodzenta, J. Synth. Met. 2017, 232, 72-78. doi:10.1016/j.synthmet.2017.07.012

45. Trefon-Radziejewska, D.; Hamaoui, G.; Chirtoc, M.; Horny, N.; Smokal, V.; Biitseva, A.; Krupka, O.; Derkowska-Zielinska, B. Mater. Chem. Phys. 2019, 223, 700-707. doi:10.1016/j.matchemphys.2018.11.054

46. Jensen, C.; Chirtoc, M.; Horny, N.; Antoniow, J. S.; Pron, H.; Ban, H. J. Appl. Phys. 2013, 114, 133509. doi:10.1063/1.4821432

47. Hamaoui, G.; Horny, N.; Hua, Z.; Zhu, T.; Robillard, J.-F.; Fleming, A.; Ban, H.; Chirtoc, M. Sci. Rep. 2018, 8, No. 11352. doi:10.1038/s41598-018-29505-4

48. Maillet, D.; André, S.; Batsale, J. C.; Degiovanni, A.; Moyne, C. Thermal Quadrupoles - Solving the Heat Equation through Integral transforms; John Wiley \& Sons Ltd.: Chichester, United Kingdom, 2000.

49. Fuente, R.; Mendioroz, A.; Apiñaniz, E.; Salazar, A. Int. J. Thermophys. 2012, 33, 1876-1886. doi:10.1007/s10765-012-1264-3

50. McNally, T.; Pötschke, P.; Halley, P.; Murphy, M.; Martin, D.; Bell, S. E. J.; Brennan, G. P.; Bein, D.; Lemoine, P.; Quinn, J. P. Polymer 2005, 46, 8222-8232. doi:10.1016/j.polymer.2005.06.094

\section{License and Terms}

This is an Open Access article under the terms of the Creative Commons Attribution License (https://creativecommons.org/licenses/by/4.0). Please note that the reuse, redistribution and reproduction in particular requires that the authors and source are credited.

The license is subject to the Beilstein Journal of

Nanotechnology terms and conditions:

(https://www.beilstein-journals.org/bjnano)

The definitive version of this article is the electronic one which can be found at: doi:10.3762/bjnano.11.14 